\title{
Impact of Peer Health Coaching on Glyce- mic Control in Low-Income Patients With Diabetes: A Randomized Controlled Trial
}

\author{
David H. Thom, MD, PbD \\ Amireb Ghorob, MPH \\ Danielle Hessler, $\mathrm{PbD}$ \\ Diana De Vore, BS \\ Ellen Chen, MD
}

Thomas A. Bodenheimer, MD

Department of Family \& Community Medicine, University of California, San Francisco, California
Conflicts of interest: authors report none.

\section{CORRESPONDING AUTHOR}

David H. Thom, MD, PhD

Department of Family \& Community Medicine

San Francisco General Hospital

1001 Potrero Ave

San Francisco, CA 94143

dthom@fcm.ucsf.edu

\begin{abstract}
PURPOSE Peer health coaches offer a potential model for extending the capacity of primary care practices to provide self-management support for patients with diabetes. We conducted a randomized controlled trial to test whether clinic-based peer health coaching, compared with usual care, improves glycemic control for low-income patients who have poorly controlled diabetes.
\end{abstract}

METHOD We undertook a randomized controlled trial enrolling patients from 6 public health clinics in San Francisco. Twenty-three patients with a glycated hemoglobin $\left(\mathrm{HbA}_{1 \mathrm{c}}\right.$ ) level of less than $8.5 \%$, who completed a 36 -hour health coach training class, acted as peer coaches. Patients from the same clinics with $\mathrm{HbA}_{1 \mathrm{C}}$ levels of $8.0 \%$ or more were recruited and randomized to receive health coaching $(n=148)$ or usual care $(n=151)$. The primary outcome was the difference in change in $\mathrm{HbA}_{1 \mathrm{c}}$ levels at 6 months. Secondary outcomes were proportion of patients with a decrease in $\mathrm{HbA}_{1 \mathrm{C}}$ level of $1.0 \%$ or more and proportion of patients with an $\mathrm{HbA}_{1 \mathrm{c}}$ level of less than $7.5 \%$ at 6 months. Data were analyzed using a linear mixed model with and without adjustment for differences in baseline variables.

RESULTS At 6 months, $\mathrm{HbA}_{1 \mathrm{c}}$ levels had decreased by $1.07 \%$ in the coached group and $0.3 \%$ in the usual care group, a difference of $0.77 \%$ in favor of coaching ( $P=.01$, adjusted). $\mathrm{HbA}_{1 \mathrm{c}}$ levels decreased $1.0 \%$ or more in $49.6 \%$ of coached patients vs $31.5 \%$ of usual care patients ( $P=.001$, adjusted), and levels at 6 months were less than $7.5 \%$ for $22.0 \%$ of coached vs $14.9 \%$ of usual care patients $(P=.04$, adjusted).

CONCLUSIONS Peer health coaching significantly improved diabetes control in this group of low-income primary care patients.

Ann Fam Med 2013;11:137-144. doi:10.1370/afm.1443.

\section{INTRODUCTION}

$\mathrm{P}$ rimary care faces serious challenges in the face of the growing demand for diabetes care. Primary care physicians are in short supply and need more time to care for patients with highly complex conditions whose costs are destabilizing US health care. ${ }^{1}$ Current numbers of nurse practitioners and physician assistants are not sufficient to provide access to the increasing demand for primary care. ${ }^{1,2}$ Registered nurses and pharmacists, who are capable of managing a large proportion of patients with diabetes, are too costly for many primary care practices. The time of medical assistants is often consumed by managing patient flow and assisting clinicians to get through the day. ${ }^{3}$ In sum, many primary care practices have no one available to provide the time-consuming counseling and teaching of self-management skills that have been shown to improve diabetes outcomes. ${ }^{4}$

To address this need, several models have been developed to provide support for patient self-management from lay workers with minimal 
training, including community health workers, lay peer educators, and peer coaches. Community health workers are from the community of the patients they assist but do not necessarily have the same disease as the patient. Though some are volunteers, most are employed by a health facility or community agency. ${ }^{5}$ Of 4 randomized controlled trials using community health workers for patients with diabetes ${ }_{,}^{6-9}$ only 1 found a significant reduction in glycated hemoglobin $\left(\mathrm{HbA}_{1 \mathrm{c}}\right)$ levels. ${ }^{9}$ In that study, community health workers visited patients at home twice a month and telephoned every 2 weeks.

Peer educators and coaches (collectively known as peer supporters), in contrast, always have the same disease as the people they assist, are usually volunteers (perhaps receiving a small monetary allowance), and generally focus on providing ongoing support for selfmanagement to a small group of clients. ${ }^{10}$ Because they experience similar challenges of living with the same chronic condition as the patients they assist, peer supporters are uniquely poised to engage and motivate other patients in self-management. ${ }^{11,12}$

Peer educators typically lead classes or support groups for individuals with diabetes, either recruited directly from the community or through 1 or more primary care clinics. Two studies of community-based peer support found a significant reduction in $\mathrm{HbA}_{1 \mathrm{c}}$ levels for patients enrolled in a peer-led support group compared with patients in the delayed support arm. ${ }^{13,14}$ A third, using an Internet-based support intervention, did not find a significant difference (possibly because the mean baseline $\mathrm{HbA}_{1 \mathrm{c}}$ level was only $\left.6.4 \%\right) .{ }^{15} \mathrm{~A}$ fourth study, with participants recruited from 24 churches, found a small but significant relative reduction in $\mathrm{HbA}_{1 \mathrm{c}}$ levels $(0.4 \%)$ at 8 months but not at 12 months. ${ }^{16}$

Although community-based peer support can be effective at improving diabetes control for the relatively small proportion of people with diabetes enrolled from the community, it is not clear whether the results would apply to the majority of patients in a clinic population. In contrast to the largely positive results from community-based peer education, studies that have evaluated clinic-based peer educator groups have had mixed results. Of 2 clinic-based peer educator interventions, 1 found no intervention effect, ${ }_{1}^{17}$ whereas the other found a significant drop in $\mathrm{HbA}_{1 \mathrm{c}}$ levels for the intervention. ${ }^{18}$ Both studies were limited by low enrollment.

Peer coaches, in contrast with peer educators, provide support to individuals, which is more flexible for patients who have difficulty attending scheduled group meetings. The few published randomized controlled trials of using peer coaching for patients with diabetes have reported mixed results; 1 found no coaching benefit, ${ }^{19}$ and 2 reported a significant benefit from coaching. ${ }^{21,20}$ The latter 2 studies were both conducted with veterans, almost all of whom were men. In addition, 1 study was restricted to African Americans ${ }^{21}$ and the second was limited by an enrollment rate of less than $25 \% .^{20}$

Patients with limited resources seen in public (safety-net) clinics often face cultural, language, and literacy barriers to self-management, making peer support particularly appealing. We conducted a randomized controlled trial of peer coaching vs usual care to test the impact of individual peer coaching on glucose control on patients with poorly controlled diabetes attending public clinics.

\section{METHODS}

The study was a randomized controlled trial comparing peer health coaching with usual care. A detailed description of the study methods has previously been published $^{22}$ and is summarized here.

\section{Setting and Participants}

All participants were low-income patients seen at 1 of 6 public health clinics that were part of the San Francisco Bay Area Collaborative Research Network. Patients who could potentially be peer coaches were identified by searching the electronic record to locate patients at each clinic who had an $\mathrm{HbA}_{\mathrm{Ic}}$ level of less than $8.5 \%$ within the past 6 months and who spoke English or Spanish. A list of patients meeting these criteria was given to their primary care clinicians, who provided a recommendation regarding the patients' suitability to coach. Additional patients were sometimes recommended by clinic staff or responded to flyers describing the study.

Patients to be randomized to receive peer coaching or usual care were identified from the electronic medical record as being potentially eligible if they spoke English or Spanish and had an $\mathrm{HbA}_{1 \mathrm{c}}$ level of $8.0 \%$ or greater within the past 6 months. All patients meeting these criteria were screened by their primary care clinicians, who could exclude any patient considered to be inappropriate, usually because of physical or mental conditions. The remaining patients were ordered randomly and approached by letter, telephone call, or in person during a clinic visit to be further screened and recruited into the study. All participants provided informed consent. The study was approved by the Committee on Human Research (Institutional Review Board) at the University of California, San Francisco (approval number H40013-34104-01-01). The authors had no conflicts of interest. 


\section{Intervention: Peer Coaching}

Potential peer coaches attended 36 hours of training over 8 weeks in either English or Spanish using a curriculum developed by the study team that included instruction in using active listening and nonjudgmental communication, helping with diabetes self-management skills, providing social and emotional support, assisting with lifestyle change, facilitating medication understanding and adherence, navigating the clinic, and accessing community resources. The curriculum can be found at http://familymedicine.medschool.ucsf.edu/ cepc/pdf/HealthCoachTrainingCurriculumMay08. pdf. Training was conducted by 2 of the investigators (A.G. and T.A.B.) and used smallgroup didactics, role-playing, and observed practice coaching sessions. Trainees who passed both a written and an oral examination became peer coaches in the study. Peer coaches interacted in person with the patients they coached at the discretion of the coach and patient, either outside the clinic by telephone or during a clinic visit; target goals for coaching sessions were telephone contact at least twice a month and 2 or more in-person contacts over 6 months. Coaches helped patients design action plans to achieve goals chosen by the patient. Trainees were paid $\$ 150$ for completing the training (regardless of whether they passed), and coaches received $\$ 25 /$ month for each client they coached.

\section{Usual Care}

Usual care included all services normally available to patients, including access to a nutritionist and diabetes educator through referral from their primary care clinician.

\section{Randomization, Enrollment, and Follow-up}

Patients who enrolled and completed baseline data collection were paid $\$ 10$ and assigned to the usual care or peer-coaching study arm using randomly ordered opaque envelopes. Patients assigned to usual care were told they would be contacted in 6 months to repeat the baseline measurements. Most patients in the coaching arm (more than $80 \%$ ) selected a peer coach from a brief coach profile, whereas the rest were assigned a peer coach based on coach availability.

Of the 37 patients who enrolled to train as coaches, 26 completed and passed the training and were designated as peer coaches. Of these 26 peer coaches, 2 dropped out for personal reasons before starting coaching.

Patients randomized to receive health coaching or usual care were enrolled from March 2010 through October 2010. As displayed in Figure 1, 814 patients
Figure 1. Screening, randomization, and completion.

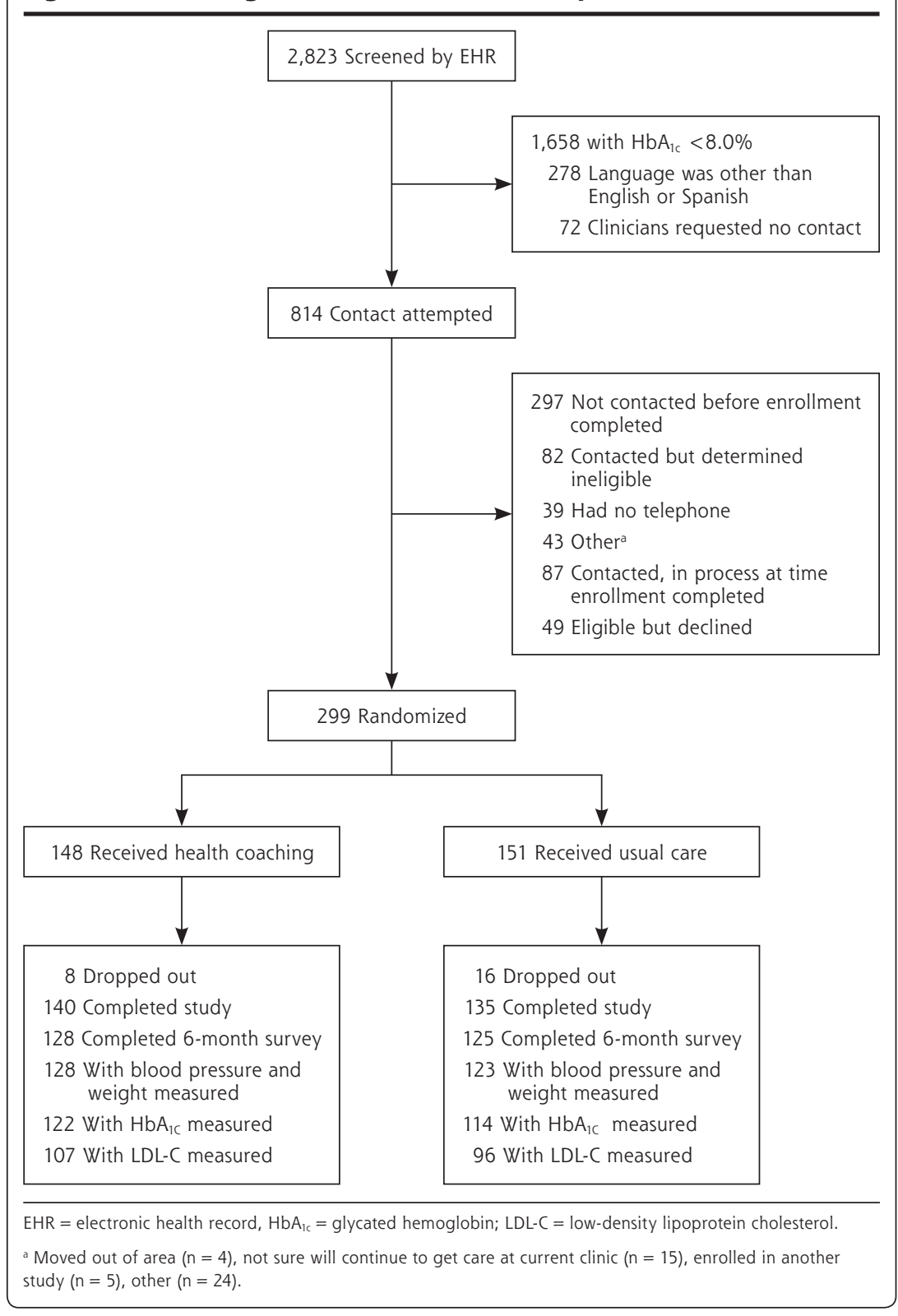


met our initial eligibility requirements, of which 297 could not be contacted. Of the 517 patients contacted, 82 were determined to be ineligible, and 87 had been contacted but were still in process at the completion of enrollment, yielding 348 patients, of whom 49 (14\%) declined to participate, and 299 were enrolled and randomized.

\section{Measures}

At enrollment, a research assistant administered a baseline questionnaire to patients that included questions about demographic characteristics, years with a diagnosis of diabetes, use of insulin, and diagnoses of hypertension or hyperlipidemia. In addition, the research assistant measured participants' height (using a tape measure and right angle), weight (using a calibrated portable scale), and blood pressure. Blood pressure was measured twice, at least 2 minutes apart, with an Omron Upper Arm Blood Pressure Monitor model HEM-711AC in the left arm after the patient had been sitting for at least 5 minutes. Blood pressure was entered as the average of the 2 readings; if the 2 systolic readings differed by more than 5 points, a third blood pressure reading was taken, and the average of all 3 readings was used.

Participants who did not have a low-density lipoprotein cholesterol (LDL-C) measurement in the past 11 months received a requisition to perform laboratory testing. All LDL-C and $\mathrm{HbA}_{1 \mathrm{c}}$ levels were measured at a central laboratory at San Francisco General Hospital using a Bio-Rad Variant II Turbo (NSGP-certified) system (Bio-Rad Laboratories, Inc). The baseline questionnaire (without the questions on demographics and health literacy) was readministered at 6 months. Weight and blood pressure were measured at 6 months, and patients received a laboratory requisition for LDL-C and $\mathrm{HbA}_{1 \mathrm{c}}$ testing. We used values for $\mathrm{HbA}_{\mathrm{ic}}$ and LDL-C that were closest in time to the target date (enrollment or 6 months after enrollment) and within the prespecified window (11 months before to 4 weeks after enrollment for LDL-C, 6 months before to 4 weeks after enrollment for $\mathrm{HbA}_{1 \mathrm{c}}$, and 5 to 9 months after enrollment for the 6-month $\mathrm{HbA}_{1 \mathrm{c}}$ and LDL-C measurements).

\section{Outcomes}

The a priori primary outcome was change in $\mathrm{HbA}_{1 \mathrm{c}}$ level from enrollment to the end of the study. Secondary outcomes were the percentage of patients whose $\mathrm{HbA}_{1 \mathrm{c}}$ level dropped by $1.0 \%$ or more and the percentage of patients with an $\mathrm{HbA}_{1 \mathrm{c}}$ level of less than $7.5 \%$ at the end of the study. Additional outcomes examined were changes in LDL-C levels, systolic blood pressure, and body mass index calculated as $\mathrm{kg} / \mathrm{m}^{2}$.

\section{Study Power and Data Analysis}

The original study protocol was to enroll 400 patients. The actual number of patients enrolled was 299 because of budgetary constraints. Assuming a difference in an $\mathrm{HbA}_{1 \mathrm{c}}$ of $0.6 \%$ between the 2 study arms and a standard deviation of $1.7 \%,{ }^{23-25}$ the 299 patients enrolled provided a power of .80 to detect a significant difference $(P<.05,2$-sided $)$ in change in $\mathrm{HbA}_{\mathrm{lc}}$ levels between study arms.

Analyses were by intention to treat and in accordance with the CONSORT guidelines for reporting results from clinical trials. ${ }^{26}$ Changes in primary and secondary outcomes were compared between study arms using a linear mixed model for continuous outcomes and logistic regression for categorical outcomes. Missing data were treated as missing (not imputed). Because the intraclass correlation coefficient for change in $\mathrm{HbA}_{1 \mathrm{c}}$ level by clinic was extremely low $(<.01)$, clustering by clinic was negligible, and clinic site was not retained in the models.

\section{RESULTS}

Less than $1 \%$ of baseline data was missing for all variables except for employment (2\%), years with diabetes (2\%) and LDL-C values (9\%). Baseline $\mathrm{HbA}_{1 \mathrm{c}}$ measurements were available a median of 30 days before enrollment in the usual care arm (interquartile range $[\mathrm{IQR}]=57$ to 4 days before enrollment) and 34 days before enrollment in the coaching arm (IQR $=74$ to 6 days before enrollment) (difference not significant). The 6 -month $\mathrm{HbA}_{1 \mathrm{c}}$ was generally measured at or close to the target date of 6 months from enrollment, with the median difference between the actual and target date being 2 days (IQR $=10$ days before to 24 days after the 6 -month date) for patients in usual care, and 0 days (IQR $=6$ days before to 24 days after the 6 -month date) for patients in the coaching group (difference not significant).

Baseline characteristics of coaches and of patients by study arm are presented Table 1 . The mean age of patients was 55 years (range 29 to 82). Slightly more than one-half of the patients were women, and approximately one-half were immigrants with a primary language other than English (usually Spanish). Patients in the coaching group were less likely to be working outside the home and to have hypertension compared with usual care patients. Coaches were approximately the same age and similar in race and ethnicity as the patients receiving coaching, but were more likely to be female and have English as their primary language. As expected, coaches also had better controlled diabetes. Of the 299 patients enrolled, 24 (8\%) did not provide any 6 -month data and were therefore considered to 
have dropped out (Figure 1). Patients who dropped out were on average younger, more likely to smoke, and less likely to report having hyperlipidemia, but did not otherwise differ significantly from patients remaining in the study. Of the 275 patients who completed the study, 253 (92\%) completed the 6-month questionnaire with a mean time from enrollment of $6.1 \pm 0.6$ months; more than $93 \%$ completed the questionnaire between 5 and 7 months. Coaches worked with a median of 7 patients $($ mean $=6.1$ ). Coached patients had a median number of 5 interactions with their peer health coach, with a range from 0 to $29 ; 123$ patients $(83 \%)$ had at least 1 interaction. Most interactions were by telephone $(76.6 \%)$ and the remainder were in-person.

Primary and secondary outcomes are displayed in Table 2. Baseline $\mathrm{HbA}_{1 \mathrm{c}}$ levels were similar in the 2 arms at baseline. Both groups experienced a decrease in $\mathrm{HbA}_{1 \mathrm{c}}$ levels, but the decrease in the $\mathrm{HbA}_{1 \mathrm{c}}$ level was significantly greater for the coached patients $(1.07 \%$ vs $0.30 \%$, adjusted difference $=0.69 \% ; P=.01$ ) A drop in $\mathrm{HbA}_{1 \mathrm{c}}$ level of $1.0 \%$ or more was seen in $49.6 \%$ patients in the coaching arm compared with $31.5 \%$ in

the usual care $\operatorname{arm}(P=.001$, adjusted $)$, and $22.0 \%$ of patients in the coaching arm achieved an $\mathrm{HbA}_{1 \mathrm{c}}$ of less than $7.5 \%$ compared with $14.9 \%$ in the usual care arm $(P=.04$, adjusted). There was no significant difference in change for LDL-C, systolic blood pressure, or body mass index after adjustment for differences in baseline variables.

\section{DISCUSSION}

This randomized controlled trial of clinic-based peer coaching for low-income, underserved patients with poorly controlled type 2 diabetes found a clinically important and statistically significant greater reduction in $\mathrm{HbA}_{1 \mathrm{c}}$ levels in patients who received peer coaching compared with those in the usual care arm. Our results are consistent with the results from 2 prior studies of peer coaching ${ }^{20,21}$ in veterans, who were almost entirely male. In the one negative randomized controlled trial of peer coaching, the coaches' role was limited to reinforcing goals set by the patients' physician ${ }^{19,27}$ in contrast to the 2 positive studies and our study, which used patient-defined goals.

The results of the current study

\section{Table 1. Baseline Characteristics of Coaches and Patients} by Study Arm

\begin{tabular}{|c|c|c|c|}
\hline Variable & $\begin{array}{l}\text { Coaches } \\
(n=24)\end{array}$ & $\begin{array}{l}\text { Coaching Arm } \\
(n=148)\end{array}$ & $\begin{array}{c}\text { Usual Care } \\
\text { Arm } \\
(n=151)\end{array}$ \\
\hline Age, mean (SD), y & $58.0(8.1)$ & $56.3(10.3)$ & $54.1(10.4)$ \\
\hline Female, \% & 66.7 & 51.4 & 53.0 \\
\hline Primary language not English, \% & 25.0 & 45.9 & 49.0 \\
\hline Born outside United States, \% & 33.3 & 47.3 & 54.0 \\
\hline Married/living as married, \% & 29.2 & 30.4 & 43.7 \\
\hline Working outside home, \% & 33.3 & 24.1 & 38.5 \\
\hline \multicolumn{4}{|l|}{ Income (per year) } \\
\hline$<\$ 10,000$ & 39.1 & 60.8 & 60.4 \\
\hline$\$ 10,000$ to $\$ 20,000$ & 43.5 & 25.7 & 28.5 \\
\hline$>\$ 20,000$ & 17.3 & 13.5 & 10.7 \\
\hline Less than high school education, \% & 12.5 & 35.6 & 37.1 \\
\hline \multicolumn{4}{|l|}{ Race/ethnicity, \% } \\
\hline White non-Hispanic & 12.5 & 11.5 & 10.0 \\
\hline White Hispanic & 20.2 & 44.6 & 48.7 \\
\hline Black/African American & 37.5 & 31.8 & 30.7 \\
\hline Other & 16.7 & 12.1 & 10.6 \\
\hline Hypertension, \% & 62.5 & 88.5 & 77.5 \\
\hline Hyperlipidemia, \% & 62.5 & 69.6 & 68.2 \\
\hline Smoked in past 30 days, \% & 16.7 & 25.7 & 26.5 \\
\hline Using insulin at baseline, $\%$ & 25.0 & 60.1 & 50.0 \\
\hline Years with diabetes, mean (SD) & $10.6(12.3)$ & $9.1(9.1)$ & $8.7(8.8$ \\
\hline $\mathrm{HbA}_{1 \mathrm{c}} \%$ & $6.88(0.76)$ & $10.14(2.01)$ & $9.84(1.95)$ \\
\hline LDL-C, mean (SD), mg/dL & $102.0(38.8)$ & $98.8(34.2)$ & $95.7(35.8)$ \\
\hline SBP, mean (SD), mm Hg & $133.5(16.8)$ & $143.0(23.9)$ & $143.4(22.3)$ \\
\hline Body mass index, mean (SD), kg/m² & $35.2(11.9)$ & $35.0(8.3)$ & $32.5(8.5)$ \\
\hline
\end{tabular}

add to the growing body of support for the effectiveness of peer coaching in improving glycemic control for patients with type 2 diabetes. Peer coaching was accepted by a large proportion of patients in this safety-net population, as well as by clinicians and clinic staff. Whether peer coaching would be as acceptable outside a veterans' or a public clinic population remains to be shown, but there does not appear to be any reason it would not. The generalizability of peer coaching to other chronic diseases is not known. Most studies of peer support have focused on patients with diabetes. Given that issues typically addressed in action plans for patients with diabetes are relevant to most chronic conditions, it seems likely that peer coaching could be effective for patients with such chronic conditions as hypertension, asthma or congestive heart failure. Many important aspects of peer coaching remain to be studied, including patients' experience with and preferences for peer coaching and how peer coaches can be more integrated into the health care team. 
Table 2. Outcomes for Patients With $\mathrm{HbA}_{1 \mathrm{c}}$ Levels Measured at 6 Months

\begin{tabular}{|c|c|c|c|c|c|c|}
\hline \multirow[b]{2}{*}{ Outcome } & \multicolumn{3}{|c|}{$\begin{array}{l}\text { Health Coaching } \\
\qquad(n=122)\end{array}$} & \multicolumn{3}{|c|}{$\begin{array}{l}\text { Usual Care } \\
(n=114)\end{array}$} \\
\hline & Baseline & $6 \mathrm{mo}$ & $\begin{array}{c}\text { Change } \\
\%\end{array}$ & Baseline & $6 \mathrm{mo}$ & $\begin{array}{c}\text { Change } \\
\%\end{array}$ \\
\hline \multicolumn{7}{|l|}{ Primary and secondary } \\
\hline $\mathrm{HbA}_{1 c}$, mean (SD), \% & $10.05(2.0)$ & $8.98(2.0)$ & $-1.07(2.8)$ & $9.85(2.0)$ & $9.55(2.3)$ & $-0.30(3.1)$ \\
\hline $\mathrm{HbA}_{1 \mathrm{c}}<7.5 \%$, No. (\%) & $5(4.1)$ & $27(22.0)$ & 17.9 & $7(6.1)$ & $17(14.9)$ & 8.8 \\
\hline $\begin{array}{l}\text { Decrease in } \mathrm{HbA}_{1 \mathrm{c}} \geq 1.0 \% \text {, } \\
\text { No. (\%) }\end{array}$ & NA & $60(49.6)$ & NA & NA & $34(31.5)$ & NA \\
\hline \multicolumn{7}{|l|}{ Additional markers } \\
\hline $\mathrm{LDL}-\mathrm{C}^{\mathrm{b}}{ }^{\mathrm{b}}$ mean $(\mathrm{SD}), \mathrm{mg} / \mathrm{dL}$ & $94.8(30.7)$ & $90.9(27.8)$ & $-3.9(41.4)$ & 96.7 (37.1) & $93.7(37.4)$ & $-3.0(52.7)$ \\
\hline $\mathrm{SBP},{ }^{c}$ mean (SD), $\mathrm{mm} \mathrm{Hg}$ & $142.8(23.1)$ & $144.2(20.1)$ & $1.4(22.3)$ & $144.0(23.2)$ & $139.7(24.1)$ & $-4.3(26.0)$ \\
\hline $\mathrm{BMI}^{\mathrm{C}}{ }^{\mathrm{c}}$ mean (SD), $\mathrm{kg} / \mathrm{m}^{2}$ & $35.1(8.3)$ & $35.0(8.2)$ & $-0.1(1.85)$ & $32.9(8.8)$ & $32.8(8.6)$ & $-0.1(1.4)$ \\
\hline \multicolumn{7}{|c|}{ 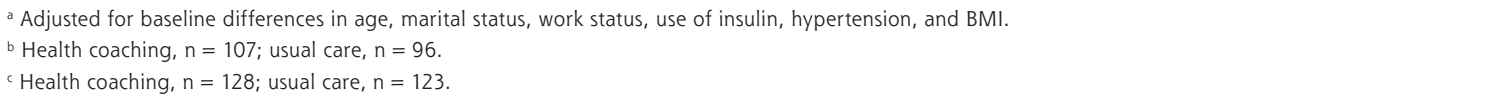 } \\
\hline
\end{tabular}

Perhaps the single most important question is how peer coaching can be supported outside research studies. Although peers coaches are generally volunteers, they need training and some level of supervision.

Most peers receive reimbursement for costs and some financial incentive. Reducing these costs would likely increase coach turnover and impair the effectiveness of the program. Moreover, successful coaching to improve patient self-management may not decrease costs in the short run, as patients are encouraged to take their medication as prescribed, get appropriate tests and preventive services, and have regular followup with their clinician.

Some potential benefits, such as reducing time needed by clinic staff to support patient self-management, are difficult to quantify. Other benefits, such as fewer emergency department visits, a lower no-show rate for appointments, or fewer complications from poorly controlled diabetes, may not outweigh the costs of increased medications. ${ }^{28}$ Long-term benefits from improved glycemic control can be calculated ${ }^{29,30}$ but are most relevant to payers and providers who pay for costs for the same patients over a long period. Nonetheless, peer coaching appears to improve glycemic control and can take the pressure off the primary care clinicians and staff to provide support for patient self-management.

The findings from the current study should be considered in the context of study's limitations. We chose to conduct the study with a diverse group of underserved patients who had poorly controlled diabetes because they represent a population at higher risk for diabetic complications and may have difficulty accessing medical care. We do not know to what extent our results will generalize to other populations, such as middle-class white patients or patients with better diabetes control. Baseline $\mathrm{HbA}_{1 \mathrm{c}}$ was measured, on average 1 month and up to 6 months before enrollment for some patients. Timing did not differ between study arms, however, and would be unlikely to bias the results. Because patients receiving peer coaching and those receiving usual care were seen at the same clinics, and often by the same clinicians, it is possible that the presence of peer coaching influenced (contaminated) the usual care group. Such an effect would be expected to make the groups more alike and make it more difficult to show a difference between groups. Our follow-up ended at 6 months; thus, we do not know whether the impact of coaching on diabetes control will diminish with time.

Patients are generally not considered as potential resources available to increase primary care capacity. The peer-coaching model creates a structure whereby volunteer peer coaches contribute to the work of primary care teams by providing one-on-one self-management support to patients. Our study shows that clinic-based peer coaches can take on this role in low-income communities and that peer coaching, when compared with usual care conducted in the same clinics, is associated with a significant improvement in patients' glycemic control.

To read or post commentaries in response to this article, see it online at http://www.annfammed.org/content/11/2/137.

Key words: peer coach; diabetes mellitus type 2; self care; primary health care; self-management support

Submitted April 1, 2012; submitted, revised, June 23, 2012; accepted July 11, 2012. 
8. Babamoto KS, Sey KA, Camilleri AJ, Karlan VJ, Catalasan J, Morisky DE. Improving diabetes care and health measures among Hispanics using community health workers: results from a randomized controlled trial. Health Educ Behav. 2009;36(1):113-126.

9. Spencer MS, Rosland AM, Kieffer EC, et al. Effectiveness of a community health worker intervention among African American and Latino adults with type 2 diabetes: a randomized controlled trial. Am J Public Health. 2011;101(12):2253-2260.

10. Boothroyd RI, Fisher EB. Peers for progress: promoting peer support for health around the world. Fam Pract. 2010;27(Suppl 1):i62-68.

11. Tang TS, Funnell MM, Gillard M, Nwankwo R, Heisler M. Training peers to provide ongoing diabetes self-management support (DSMS): results from a pilot study. Patient Educ Couns. 2011;85(2): 160-168.

12. Fisher EB, Earp JA, Maman S, Zolotor A. Cross-cultural and international adaptation of peer support for diabetes management. Fam Pract. 2010;27(Suppl 1):i6-i16.

13. Lorig K, Ritter PL, Villa F, Piette JD. Spanish diabetes self-management with and without automated telephone reinforcement: two randomized trials. Diabetes Care. 2008;31(3):408-414.

14. Lorig K, Ritter PL, Laurent DD, et al. Online diabetes self-management program: a randomized study. Diabetes Care. 2010;33(6): 1275-1281.

Funding support: The study was funded by a grant from the American Academy of Family Physicians.

Disclaimer: The American Academy of Family Physicians approved the study design but had no role in the conduct of the study, data analysis, or reporting of the results.

Acknowledgments: We would like to acknowledge the members of our study staff whose hard work made this study possible: Marissa Pimental, Denise De Vore, Maria Vivas, Victoria Ngo, and Russell Yamamoto. The study clinical sites are part of the San Francisco Bay Area Collaborative Research Network.

Clinical Trials Identifier: NCT01040806. http://clinicaltrials.gov/ct2/show/ NCT01040806?term $=$ NCT01040806\&rank $=1$

\section{References}

1. Bodenheimer T, Pham HH. Primary care: current problems and proposed solutions. Health Aff (Millwood). 2010;29(5):799-805.

2. Abram M, Nuzum R, Mika S, Lawlor G. Realizing Health Reform's Potential: How the Affordable Care Act Will Strengthen Primary Care and Benefit Patients, Providers, and Payers. Vol 1. Publication 1466. New York, NY: Commonwealth Fund; 2011.

3. Ferrer RL, Mody-Bailey $P$, Jaén $C R$, Gott $S$, Araujo $S$. A medical assistant-based program to promote healthy behaviors in primary care. Ann Fam Med. 2009;7(6):504-512.

4. Norris SL, Engelgau MM, Narayan KM. Effectiveness of selfmanagement training in type 2 diabetes: a systematic review of randomized controlled trials. Diabetes Care. 2001;24(3):561-587.

5. Rosenthal EL, Brownstein JN, Rush $\mathrm{CH}$, et al. Community health workers: part of the solution. Health Aff (Millwood). 2010;29(7):1338-1342.

6. Holtrop JS, Hickner J, Dosh S, Noel M, Ettenhofer TL. Sticking to it-diabetes mellitus: a pilot study of an innovative behavior change program for women with type 2 diabetes. J Health Educ. 2002;33(3):161-166.

7. Gary TL, Bone LR, Hill MN, et al. Randomized controlled trial of the effects of nurse case manager and community health worker interventions on risk factors for diabetes-related complications in urban African Americans. Prev Med. 2003;37(1):23-32.

15. Lorig K, Ritter PL, Villa FJ, Armas J. Community-based peer-led diabetes self-management: a randomized trial. Diabetes Educ. 2009; 35(4):641-651.

16. Samuel-Hodge CD, Keyserling TC, Park S, Johnston LF, Gizlice Z, Bangdiwala SI. A randomized trial of a church-based diabetes selfmanagement program for African Americans with type 2 diabetes. Diabetes Educ. 2009;35(3):439-454.

17. Smith SM, Paul G, Kelly A, Whitford DL, O'Shea E, O'Dowd T. Peer support for patients with type 2 diabetes: cluster randomised controlled trial. BMJ 2011;342:d715

18. Philis-Tsimikas A, Fortmann A, Lleva-Ocana L, Walker C, Gallo LC. Peer-led diabetes education programs in high-risk Mexican Americans improve glycemic control compared with standard approaches: a Project Dulce promotora randomized trial. Diabetes Care. 2011;34(9):1926-1931.

19. Dale J, Caramlau I, Sturt J, Friede T, Walker R. Telephone peerdelivered intervention for diabetes motivation and support: the telecare exploratory RCT. Patient Educ Couns. 2009;75(1):91-98.

20. Heisler M, Vijan S, Makki F, Piette JD. Diabetes control with reciprocal peer support versus nurse care management: a randomized trial. Ann Intern Med. 2010;153(8):507-515.

21. Long JA, Jahnle EC, Richardson DM, Loewenstein G, Volpp KG. Peer mentoring and financial incentives to improve glucose control in African American veterans: a randomized trial. Ann Intern Med. 2012;156(6):416-424.

22. Ghorob A, Vivas MM, De Vore D, Ngo V, Bodenheimer T, Chen E, Thom $\mathrm{DH}$. The effectiveness of peer health coaching in improving glycemic control among low-income patients with diabetes: Protocol for a randomized controlled trial. BMC Public Health. 2011; $11: 208$.

23. Deakin TA, Cade JE, Williams R, Greenwood DC. Structured patient education: the diabetes X-PERT Programme makes a difference. Diabet Med. 2006;23(9):944-954.

24. Kulzer B, Hermanns $N$, Reinecker $H$, Haak T. Effects of self-management training in Type 2 diabetes: a randomized, prospective trial. Diabet Med. 2007;24(4):415-423.

25. Deakin T, McShane CD, Cade JE, Williams RD. Group based training for self-management strategies in people with type 2 diabetes mellitus. Cochrane Database Syst Rev. 2005;(2):CD003417. 
26. Schulz KF, Altman DG, Moher D; CONSORT Group. CONSORT 2010 statement: updated guidelines for reporting parallel group randomized trials. Ann Intern Med. 2010;152(11):726-732.

27. Dale J, Caramlau I, Docherty A, Sturt J, Hearnshaw H. Telecare motivational interviewing for diabetes patient education and support: a randomised controlled trial based in primary care comparing nurse and peer supporter delivery. Trials. 2007;8:18. 10.1186/1745-6215-8-18.

28. Gilmer TP, Philis-Tsimikas A, Walker C. Outcomes of Project Dulce: a culturally specific diabetes management program. Ann Pharmacother. 2005;39(5):817-822.

29. Gilmer TP, Roze S, Valentine WJ, et al. Cost-effectiveness of diabetes case management for low-income populations. Health Serv Res. 2007:42(5):1943-1959.

30. Gillespie P, O'Shea E, Paul G, O'Dowd T, Smith SM. Cost effectiveness of peer support for type 2 diabetes. Int J Technol Assess Health Care. 2012;28(1):3-11

\section{CHANGE-OF-ADDRESS FORM FAMILY MEDICINE}

Please complete this form and mail to the following address or fax to Annals Circulation at 913-906-6080:

Annals of Family Medicine, Circulation Department, 11400 Tomahawk Creek Pkwy, Leawood, KS 66211-2680

Check if member of sponsoring organization:

$$
\begin{array}{lc}
\square \text { AAFP } & \square \text { ABFM } \square \text { STFM } \square \text { ADFM } \\
\square \text { AFMRD } & \square \text { NAPCRG } \square \text { CFPC }
\end{array}
$$

ID number from label on your journal cover

OLD Information (Please print.)

Name

Company (if applicable)

Address (Street plus Apt or Ste)

City

Country

Telephone

E-Mail
NEW Information (Please print.)

\begin{tabular}{ll}
\hline Name \\
\hline Company (if applicable) \\
\hline Address (Street plus Apt or Ste) & \\
\hline City & Postal Code (9-digit ZIP for US) \\
\hline Country & Fax \\
\hline Telephone & \\
\hline E-Mail
\end{tabular}

